\section{Transdisciplinary Processes for Sustainable Development}

\author{
Marc Craps
}

Faculty of Economics and Business Management, Centre for Corporate Sustainability, KU Leuven, Brussels, Belgium

\section{Definition}

Transdisciplinary processes for Sustainable Development refer to the relational characteristics of the collaboration between academic and nonacademic actors that are necessary to address the complex conceptual, value-laden and actiondriven challenges of sustainable development.

\section{Introduction}

Sustainable development assumes a holistic approach to the complex human-ecosystem interrelationships. Such an approach requires an intense collaborative effort between a variety of academic and nonacademic actors with different knowledge traditions, perspectives on, and interests in the way they experience and frame sustainability-related issues. This is contrary to the dominating practices in higher education based on specialization in disconnected disciplines. Higher education requires research and learning practices that stimulate specialists from different fields to engage in collaborative activities with nonacademic actors that contribute to sustainable development. Due attention has to be given to the qualities of the relationships between the involved actors. These qualities have to be considered in relation with the conceptual and action-driven aspects of collaboration and sustainability (Senge et al. 2007).

In the following sections, first a socialrelational process perspective on collaboration is explained, and then its relevance for sustainable development is clarified. Different perspectives (individual, interactional, thematic, and contextual) on research are identified that enable a variety of academic and nonacademic actors to engage in a joint exploration of complex realities. Subsequently, the relational tasks and challenges in the consecutive phases of a collaborative research process are described. Finally we give attention to issues of leadership and boundary management in transdisciplinary processes for sustainable development.

\section{A Social-Relational Perspective on Transdisciplinary Collaboration for Sustainable Development}

Various authors argue for giving due importance to the social-relational characteristics of collaborative processes in transdisciplinary research for sustainable development. Indeed, transdisciplinary research might be quite demanding for the 
quality of the relations between different research teams and with external stakeholders (O'Brien et al. 2013; Cundill et al. 2015; Lawrence 2015; Edelenbos et al. 2017). Collaboration is then conceived as a process in search for synergetic solutions between different actors involved in a shared complex problem through the joint appreciation of different but complementary viewpoints (Gray 1989; Huxham and Vangen 2005; Gray and Purdy 2018). Through an emergent and possibly conflictive process, actors increase their insights in the intertwined nature of complex problems and their collaborative capacities while negotiating mutually beneficial agreements.

Collaborations for sustainability draw together partners with very different but relevant attributes. "The point of working with someone else is that they have a perspective, skills, resources or some other attribute that contributes something relevant to addressing the research problem, either in improving or understanding about it or in implementing that understanding in decisions and action" (Bammer 2008). Participants acknowledge the advantages of hearing different perspectives and the opportunity to gain a better understanding of others' views (O'Brien et al. 2013).

In these collaborative research endeavors for sustainability, universities have to partner with business companies, governments, and NGOs to confront complex sustainability-related problems for which isolated efforts are inadequate. Such cross-sectoral groups, with a shared commitment towards a joint socioecological challenge, have to engage with one another to coproduce knowledge for policies and practical applications. Barriers between traditional knowledge roles - researchers as opposed to stakeholders - and between knowledge forms - scientific knowledge as opposed to experiential knowledge - (O'Brien et al. 2013) must be broken down. The participants will be involved in an ongoing, iterative process of issue framing, knowledge production, and knowledge application. As they are operating in different areas of practice, the jointly developed knowledge will have to be applicable in such varied areas as science, state institutions, commercial enterprises, and civil society activism (Senge et al. 2007; Cundill et al. 2015).
The relational qualities of the interactions among the participants must stimulate them to reflect on the - often implicit - mental models of their discipline, and on how these different mental models can be linked with each other, to generate a shared vision (Senge et al. 2007). The insight that the relational qualities in small group processes is decisive for the effectiveness of organizations goes back to the seminal work on Group Dynamics and Organization Development by Kurt Lewin and followers (Edgar Schein, Ronald Lippitt, Chris Argyris, amongst others). Although Organization Development is best known in management studies, Lewin conceived his processdriven intervention methodology originally in contexts of social development, to deal with issues like racism and authoritarianism (Cooke 1998). The democratizing and participatory vocation of Organization Development is part of its DNA and has inspired influential contemporary scholars like Peter Senge, Otto Scharmer, and Etienne Wenger to further develop it into innovative collaborative methodologies for broad sustainability-related challenges on the societal level (Wenger 1998; Senge et al. 2007; Scharmer and Kaufer 2013).

Senge et al. (2007) argue for a transformational model of collaboration, in contrast with a transactional model, when sustainable development is at stake. Transactional collaborative networks operate like markets: they are only viable when actors perceive that the benefits of collaborating exceed the costs of the invested resources, time, and risks. From this perspective, a collaborative effort is attractive for participants when there is a compelling value proposition, a clear "business case" for them. Transactional mechanisms may function to improve existing systems by enhancing their (eco-)efficiency; however, they are not able to drive the transformational changes at system level necessary to reach sustainable development. By contrast, a transformational logic revolves around a larger purpose that matters not only to all the direct participants in the collaboration but also to society at large, including vulnerable and voice-less social groups, and all living beings on our planet, including future generations. A transformational logic recognizes the 
inalienable rights of all living beings to survive and flourish as part of a healthy global ecosystem, even if they do not have the possibility to defend these rights. Participants in a transformational collaboration are not indifferent to their own benefits and costs, but their primary motivation to collaborate comes from a commitment to a transcendent aim of generating sustainable solutions, and from the awareness of the long-term strategic importance of the collaboration for their own organizations and for the larger system in which they are embedded (Folke et al. 2009; Craps et al. 2016; Williams et al. 2017).

\section{Different Perspectives on Research to Engage Academic and Nonacademic Actors}

One of the main challenges of transdisciplinary research for sustainability consists in linking the generalizing claims of the academic scholars with the experiential and contextualized insights of other knowledge holders, like local community members, social activists, citizen scientists, etc. Actively involving local actors and other stakeholders in the study of their own reality is indeed necessary to address adequately the context-dependent issues of social-ecological systems and the interests of these stakeholders as they map out their future livelihoods (Chaffin et al. 2016). Contextualization also makes knowledge "actionable" for the different involved actors (Dewulf et al. 2005), by connecting the interests of the scientific scholars with the interests of the other stakeholders (Aram 2004; Klein 2015).

Transdisciplinary research can draw on a long tradition in participatory action research (Whyte 1989). In the domain of public policy, Arnstein's (1969) seminal "ladder of participation" has greatly influenced thinking about participation in research and policy making. This ladder indicates increasing levels of public participation. The lowest level of participation in research by an actor consists in just being informed about the research and passively giving information, but without any influence on the research question and the way results will be applied. The highest level consists in determination of the research agenda, selforganization of the research, and decision-making regarding the consequences of the outcomes by the stakeholder community (Arnstein 1969; Craps et al. 2016).

These increasing levels of participation and collaboration of academic and nonacademic actors in joint research to grasp complex realities imply the combination of different perspectives on knowledge acquisition. The distinction between an individual, an interactional, a thematic, and a contextual perspective, identified by Ruth Cohn in the Theme-Centred-Interaction model (Lawrence 2015) is useful for this purpose. These perspectives are related with the distinction in action research between first person (subjective) knowledge, second person (intersubjective) knowledge, and third person (objectifying) knowledge (Chandler and Torbert 2003). Otto Scharmer conceives these perspectives in a similar way as different levels of awareness about the needs of society to attain sustainable development (Scharmer and Kaufer 2013). Each perspective puts its own requirements on the transdisciplinary collaboration. In the following paragraphs four complementary research perspectives and their requirements are explained more in detail.

Research from an individual perspective helps the researcher to become aware of one's deeper interests and needs (the "I" level). Chandler and Torbert (2003) describe first-person research as: encompassing skills and methods that address the ability of the researcher to foster an inquiring approach to his or her own life, to act consciously, and to assess effects in the outside world while acting. The key in these practices is to reflect critically on issues that make us vulnerable and to reconsider the ways in which we live our lives. The increasing interest in meditative practices like mindfulness, inspired by Buddhist and other spiritual traditions, by individuals and groups also in academic environments dedicated to sustainability-related issues, can be linked with this interest in cultivating "I"-knowledge to connect deeper with oneself, the others, and the whole ecosystem (Scharmer and Kaufer 2013). 
Transdisciplinary research from an interactional perspective reflects on how the relations between the involved actors affect the outcomes of their joint initiative (the "We" level). Secondperson research involves creating communities of inquiry in which the participants reflect on the inclusion and exclusion of actors, explore the undesirable side effects of the application of their models for other actors, deal adequately with power disparities and conflicting interests and talk about issues of leadership, dependency, and counter-dependency in the group process. The aim is to enhance opportunities for mutual transformations. This process must take place in a supportive, self-disclosing, and open way to support reflexive social learning (Argyris and Schön 1978; Chandler and Torbert 2003). Below the importance of reflexive social learning for sustainable development in higher education will be explained more in-depth.

Research from a thematic perspective analyzes shared purposes and concerns (the "It" level). In third-person research, researchers analyze a reality from the outside, with specific instruments and following rules which are agreed upon in a disciplinary community. It has proven its value to generate instrumental knowledge for the creation and steering of "simple" systems, according to a linear cause-effect logic, according to a mechanistic metaphor of reality. This external perspective on reality is insufficient when we have to understand, learn about, and adapt to complex changing systems, the core challenge of sustainability. It has then to be complemented with an agent-based (inter-subjective) perspective "from within." However a (post-)positivist approach, which is still dominating the majority of academic natural and social sciences, tends to consider an objectifying third person perspective as the only one to generate valid knowledge. It does not encourage integration with first-person research, in which researchers reflect on their own practices, and with second-person research, which pays attention to the interactions between the researchers and with the subjects they are studying (Chandler and Torbert 2003). As a consequence, a narrow positivist approach to the study of sustainable development may hinder the necessary transdisciplinary collaboration. Valid third-level knowledge, based on critical analysis and fact checking, is necessary but it has to be exchanged in high-quality dialogues among knowledgeable and interested participants, who listen "with an open heart and open mind" (first level) and deep empathy for the others (second level) (Scharmer and Kaufer 2013).

According to Otto Scharmer's U-theory (2013), the participants in a collaborative research process should evolve through and beyond the former stages to arrive at a stage of "generative listening." The collaborating group will experience then collectively a deeper connection with the broader context and will become deeply aware of its systemic embeddedness (fourth level, global/contextual). This stimulates the participants to grasp not only what has happened in the past, and the reality as it is now, but also a reality that is becoming and that could be possible in the future. Research is then linked with action. Once aware of "the deeper realm of emergence," groups engage in co-creating solutions through prototyping and scaling up successful alternatives that contribute to the sustainability of the broader eco-system. (Scharmer and Kaufer 2013)

\section{Relational Challenges Throughout Collaborative Research Processes}

Various authors have described models of collaborative research processes that describe distinct periods of sequential activities. Lawrence (2015) describes a seven step process: (1) identification of partner organizations, (2) identification of cases, (3) formulation of research questions and the boundaries of each case, (4) choice of analytical frameworks, (5) data collection, (6) analysis of case studies and synthesis of results, and (7) discussion and communication of results. Ayre and Nettle (2015) propose a model of a dynamic process for knowledge integration in five phases: (1) establishing the imperative for integration, (2) coordinating different disciplinary and other knowledge commitments, (3) consolidating arrangements for integration, (4) prioritizing outputs from integration, and (5) representing outputs 
of integration. Gray $(1989,2008 \mathrm{~b})$ proposes a more generic four phase model for collaborative problem solving and decision-making: (1) problem setting, (2) direction setting, (3) implementation, and (4) institutionalization. The critical tasks in the problem-setting phase include identifying the relevant partners and getting them to commit to a collaborative partnership. Direction setting involves exploring the issues and reaching the necessary agreements among the participants to address these issues. Implementation entails putting those agreements into place and ensuring follow-up of these agreements. Institutionalization has to capture structuring and regularization of ongoing interactions among stakeholders and learning for the replication of similar partnerships in other contexts.

These models pay limited attention to the relational process between the participants, that - as described above - is of decisive importance in transdisciplinary research for sustainable development. Bouwen and Taillieu (2004) observe that natural scientists and engineers have a tendency to restrict their attention to the content of the problems. The distinction made by these authors between activities focusing on the content of the problems and "relational" activities in transdisciplinary projects is useful to highlight the challenges and tasks to deal adequately with the social relations between the partners in a collaborative research process: (1) getting attention and raising awareness of all relevant stakeholders, (2) mobilizing these stakeholders and getting their commitment to collaborate, (3) legitimating conveners and stakeholders, (4) dialoguing to explore the diversity of knowledge frames and interests, (5) connecting frames and interests, (6) negotiating roles and identities, (7) guaranteeing commitment of constituencies for the implementation of the proposed solutions, and (8) aligning efforts and agreements. Although task content and social relations can be distinguished analytically, they can and should not be separated in practice. For that reason, Bouwen and Taillieu (2004) argue for "relational practices," which are task-oriented actions that foster the collaborative process by the high quality of the relations between the involved actors and the space for reflexivity.
Investing sufficient time and resources for face-to-face meetings between participants in a transdisciplinary project is of fundamental importance to cultivate these high-quality relations between research groups and with external stakeholder groups. For the same reason, long-term engagement in transdisciplinary projects is argued for as developing trust and mutual understanding is a slow and tricky process (Edelenbos et al. 2017). Joint field visits of researchers belonging to different disciplines, together with external stakeholders, are repeatedly mentioned as important opportunities, not only to know each other better but also to exchange contextualized information (Bouwen 2001; Dewulf et al. 2005; O'Brien et al. 2013). Participatory mapping techniques are highlighted because of their potential to integrate scientific information with stakeholder knowledge, contributing to a sense of legitimacy and inclusive ownership of the final products (Cundill et al. 2015).

Sufficient concern should also be given to the fundamental role that reflexivity plays in transdisciplinary research for sustainability (Gerritsen et al. 2013; Cundill et al. 2015; Popa et al. 2015). Popa et al. (2015) define reflexivity in a broad sense as the acknowledgement, critical deliberation, and mutual learning on values, assumptions, and understandings that enables the generation of "new meanings, new heuristics, and new stakeholder identities." The need for a more systematic integration of reflexive processes into transdisciplinary science can be advocated on epistemological, normative, and pragmatic grounds (Popa et al. 2015). The epistemic role focuses on extending the community in order to be more able to grasp the complex and uncertain nature of the problem situation. The normative role emphasizes the importance of democratic participation, social relevance, and legitimacybuilding. The pragmatic role considers the mobilization of public support and public trust in the expertise that is developed and in policy interventions that rely on such expertise. This leads the authors to distinguish four purposes for reflexivity in transdisciplinary research: (1) to develop a shared understanding of a problem, (2) to reflect on the social relevance of the problem framing, 
(3) to set up joint social experiments and collective learning processes, and (4) to create a research agenda with a critical and transformative character. This last form of reflexivity does not only include acknowledging the values, ideologies, and power structures that shape the organization of the research process but also clarifying and developing agreements on an agenda of social change and sustainability transitions. For these purposes, a combination of conventional consensus-oriented deliberative approaches and more open-ended, action-oriented, transformative approaches to reflexivity is recommended.

\section{Leading and Facilitating Transdisciplinary Communities}

Various authors point to the inspiring concept of "communities of practice" for transdisciplinary research teams (Dewulf et al. 2005; Cundill et al. 2015; Lawrence 2015; Polk 2015). This concept draws on the situated learning theory of Lave and Wenger. It was further developed by Wenger $(1998,2000)$ to deal with the challenges of sustainable development. Communities of practice are emergent social entities resulting from interactions that arise out of the concerted efforts and shared interests of groups of individuals to engage in a process of collective learning. Learning communities become evident when people start asking for help and offering help to each other, and openly discuss real problems with which they are confronted. Over time, they nurture common commitment and relationships based on respect and mutuality (Senge et al. 2007).

Communities of practice are characterized by different levels of participation. Often only a relatively small core group is highly active. The core members provide informal leadership and ensure the legitimacy of the community to the outside world. Other "full" members participate regularly and contribute meaningfully but without the same engagement as the core members. A third category of "peripheral" members is also important for transdisciplinary communities of practice because they tend to use the knowledge produced by the learning community in their policy work. In this way, they enhance the reputation of the transdisciplinary community in terms of its credibility, legitimacy, and saliency (Cundill et al. 2015). Peripheral members may also transform into full or core members and in this way they expand and replenish the membership of the community. Other people may not be considered as members but have an interest in the activities of the community. At any moment, they may become peripheral, full, or even core members, depending on the evolving topics with which a community is dealing. Some people will move through all these layers of membership over time, at times playing an active role during a given topic or activity and at other times playing a more passive role. For that reason, successful communities of practice encourage peripheral participation and develop consciously opportunities, for those on the sidelines to contribute (Wenger 2000).

As learning in communities of practice is a result of the interest and the initiative of its participants, such communities cannot be imposed by an external authority. Setting up a transdisciplinary research project or program will not in itself generate transdisciplinary learning (Senge et al. 2007). But although formal administrative authorities do not lead the learning process of communities of practice, they still have an important role in it. A relational process perspective on transdisciplinarity draws the attention to how leadership works in the interplay between different actors to generate learning between different groups. Complexity Leadership Theory (CLT) offers a suitable framework for this purpose, as it views leadership as resulting from the concerted and collective activities of sets of network members who actively strive for innovative solutions, provoking a collective impulse for action and change (Uhl-Bien 2006). According to CLT, three complementary leadership functions are situated in different types of leadership networks: administrative leadership in formal networks, adaptive leadership in change alliances, and enabling leadership in shadow networks. The main functions and tasks of these three different leadership networks will be presented in the following paragraphs. 
Administrative leadership refers to the power and authority derived from top positions in hierarchical structures. Members in formal managerial positions can allocate resources to different parts of the organization by their strategic planning. To favor transdisciplinary learning, administrative leaders, who are mostly concerned with the survival and continuity of their organization, must be aware of the necessity of transformational changes in their organization to respond to the challenges of the broader context in which they are embedded. They have to assign resources to innovative, experimental niches in their organization, functioning with informal structures, and open boundaries.

Adaptive leadership refers to the interactive and generative dynamic that takes place throughout the organization in innovative "change alliances," emerging out of the clash of discordant ideas, knowledge, and initiatives. This is the kind of leadership enacted by the core members of transdisciplinary research and learning communities. Because of the dynamic and "ad-hoc" nature of these groups, they depend largely on the quality of the relations of its members and the degree with which they can dialogue, listen to each other, and acknowledge one another's ideas (Bouwen and Taillieu 2004). Leadership here consists largely in visioning as an appreciative task that appeals to participants unleashing their curiosity and creativity to generate scientific breakthroughs and a new understanding of a specific problem area by connecting different types of knowledge (Gray 2008a). This implies promoting divergent thinking, risk taking, and challenging established methods.

Enabling leadership, the third leadership function in the CLT framework, contributes to the transdisciplinary process by facilitating the relations inside transdisciplinary teams as well as between these teams and the administrative leaders of their constituencies. Enabling leaders can fulfil several tasks to improve transdisciplinary processes, like: designing meetings with external stakeholders, determining what ground rules might be useful, developing trust among the partners, caring for the stability of the group even when members come and go, mediating conflicts that are likely to arise as members strive to understand and integrate concepts, frameworks, and methodologies that may threaten their disciplinary comfort zones and ensuring that there is effective communication and that necessary information is transferred among the partners (Gray 2008a).

Enabling leadership calls the attention to the importance of boundary spanning and brokering in transdisciplinary initiatives. Transdisciplinary groups can indeed be considered as boundary organizations that exist at the borders of different social worlds and mediate the interactions between these worlds despite their diverse purposes, incongruent values, or eventual mutual incomprehension (Cundill et al. 2015). They can exist with the help of boundary objects, boundaryspanning activities, and brokers.

Boundary objects are models, classification systems, interactive maps, and so forth that enable different communities to interact despite differences (Wenger 2000; Craps et al. 2004; Cundill et al. 2015). Boundary-spanning activities are critical for transdisciplinary initiatives because they pass information from, and to, groups outside their boundaries. Gray (2008b) identifies the following boundary-spanning tasks as key for transdisciplinary teams are: gaining and maintaining sound institutional commitment and support, acquiring funds to manage emerging areas of research and training, devoting adequate attention to and securing funds for infrastructure, and building bridges to other centers and new disciplines.

Brokers are persons that build linkages and increase information flows among previously unrelated parties (Gray 2008b). Because they occupy "structural holes" in social networks, they have access to a wider array of information than others within a network and, because they have one foot in each of several groups, they can decipher differences and translate among them. They can also help solving misunderstandings and overcoming the tensions due to power and status differences among diverse groups. Brokers with experience in both scientific and policy communities, can improve the integration of policy considerations in the transdisciplinary knowledge (Cundill et al. 2015). Organized groups of 
engaged and well-informed local inhabitants can fulfil essential brokering functions by bringing the worries of the local communities under the attention of the transdisciplinary teams (Sips et al. 2013). To the extent that the members of transdisciplinary teams have diverse contacts outside their team, they may all leverage various brokerage roles to import novel insights into the team (Gray 2008a).

\section{References}

Aram JD (2004) Concepts of interdisciplinarity: configurations of knowledge and action. Hum Relat 57:379. https://doi.org/10.1177/0018726704043893

Argyris C, Schön DA (1978) Organizational learning II. Addisson-Wesley, Reading

Arnstein S (1969) A ladder of participation. J Am Plan Assoc 35(4):216-224

Ayre M, Nettle R (2015) Doing integration in catchment management research: insights into a dynamic learning process. Environ Sci Policy. Elsevier Ltd 47:18-31. https://doi.org/10.1016/j.envsci.2014.10.011

Bammer G (2008) Enhancing research collaborations: Three key management challenges. Res Policy 37(5):875-887. https://doi.org/10.1016/j.respol.2008.03.004

Bouwen R (2001) Developing relational practices for knowledge intensive organizational contexts. Career Dev Int 6(7):361-369. https://doi.org/10.1108/EUM 0000000006057

Bouwen R, Taillieu T (2004) Multi-party collaboration as social learning for interdependence: developing relational knowing for sustainable natural resource management. J Community Appl Soc Psychol 14(March):137-153

Chaffin BC et al (2016) Transformative environmental governance. Annu Rev Environ Resour 41:399-423. https:// doi.org/10.1146/annurev-environ-110615-085817

Chandler D, Torbert B (2003) Transforming inquiry and action: interweaving 27 flavors of action research. Action Res 1(2):133-152. https://doi.org/10.1177/1476750303 0012002

Cooke B (1998) Participation, "process" and management: lessons for development in the history of Organization Development. J Int Dev 10(1):35-54

Craps $M$ et al (2004) Constructing common ground and re-creating differences between professional and indigenous communities in the Andes. J Community Appl Soc Psychol 14(5):378. https://doi.org/10.1002/casp.796

Craps M, Grieten S, Bouwen R (2016) Co-creating the future now. In: Achten V, Bouckaert G, Schokkaert E (eds) A truly golden handbook. The scholarly quest for Utopia. Leuven University Press, Leuven, pp 248-261

Cundill G, Roux DJ, Parker JN (2015) Nurturing communities of practice for transdisciplinary research. Ecol Soc 20(2). https://doi.org/10.5751/ES-07580-200222
Dewulf A et al (2005) How indigenous farmers and university engineers create actionable knowledge for sustainable irrigation. Action Res 3(2):175-192. https:// doi.org/10.1177/1476750305052141

Edelenbos J, Bressers N, Vandenbussche L (2017) Evolution of interdisciplinary collaboration: what are stimulating conditions? Sci Public Policy 44(July):451-463. https:// doi.org/10.1093/scipol/scw035

Folke C, Chapin FS, Olsson P (2009) Transformations in ecosystem stewardship. In: Chapin FS, Olsson P (eds) Principles of ecosystem stewardship. Springer, New York, pp 103-125. https://doi.org/10.1007/978-0387-73033-2

Gerritsen AL, Stuiver M, Termeer CJAM (2013) Knowledge governance: an exploration of principles, impact, and barriers. Sci Public Policy 40(5):604-615. https:// doi.org/10.1093/scipol/sct012

Gray B (1989) Collaborating. Finding common ground for multi-party problems. Jossey-Bass, San Francisco

Gray B (2008a) Enhancing transdisciplinary research through collaborative leadership. Am J Prev Med 35(2 Suppl): S124-S132. https://doi.org/10.1016/j.amepre.2008.03.037

Gray B (2008b) The process of partnership construction: anticipating obstacles and enhancing the likelihood of successful partnerships for sustainable development. In: Partnerships, governance and sustainable development. Reflections on theory and practice. Edward Elgar, Cheltenham, pp 29-48

Gray B, Purdy J (2018) Collaborating for our future. Multistakeholder partnerships for solving complex problems. Oxford University Press, Oxford

Huxham C, Vangen S (2005) Managing to collaborate. Routledge, London

Klein JT (2015) Reprint of "Discourses of transdisciplinarity: looking back to the future". Futures. Elsevier Ltd 65:10-16. https://doi.org/10.1016/j.futures.2015.01.003

Lawrence RJ (2015) Advances in transdisciplinarity: Epistemologies, methodologies and processes. Futures 65:1-9. https://doi.org/10.1016/j.futures.2014.11.007

O’Brien L, Marzano M, White RM (2013) "Participatory interdisciplinarity": towards the integration of disciplinary diversity with stakeholder engagement for new models of knowledge production. Sci Public Policy 40(1):51-61. https://doi.org/10.1093/scipol/scs 120

Polk M (2015) Transdisciplinary co-production: designing and testing a transdisciplinary research framework for societal problem solving. Futures. Elsevier Ltd 65: 110-122. https://doi.org/10.1016/j.futures.2014.11.001

Popa F, Guillermin M, Dedeurwaerdere T (2015) A pragmatist approach to transdisciplinarity in sustainability research: from complex systems theory to reflexive science. Futures. Elsevier Ltd 65:45-56. https://doi. org/10.1016/j.futures.2014.02.002

Scharmer O, Kaufer K (2013) Leading from the emerging future. From ego-system to eco-system economies. Berrett-Koehler Publishers, San Francisco

Senge PM et al (2007) Collaborating for systemic change. Sloan Manag Rev 48(Winter):44

Sips K, Craps M, Dewulf A (2013) Local participation in complex technological projects as bridging between 
different communities in Belgium. Knowl Manag Dev J 9(3):95-115

Uhl-Bien M (2006) Relational leadership theory: exploring the social processes of leadership and organizing. Leadersh Q 17(6):654-676. https://doi.org/10.1016/j.lea qua.2006.10.007

Wenger E (1998) Communities of practice. Learning, meaning and identity. Cambridge University Press, Cambridge
Wenger E (2000) Communities of practice and social learning systems. Organization 7(2):225-246. https://doi. org/10.1177/135050840072002

Whyte WF (1989) Advancing scientific knowledge through participatory action research. Sociol Forum 4(3):367-385

Williams A et al (2017) Systems thinking: a review of sustainability management research. J Clean Prod. Elsevier Ltd 148:866-881. https://doi.org/10.1016/j.jclepro.201 7.02.002 